\title{
VISITAS MONITORADAS: UM CONHECIMENTO PARA ALÉM DOS MUROS DA ESCOLA ${ }^{1}$
}

\author{
José Gean Belchior Gomes ${ }^{2}$ \\ Cleire Lima da Costa Falcão ${ }^{3}$
}

\section{RESUMO}

O presente artigo constitui uma etapa da pesquisa realizada no Programa de Educação em Solos: conhecer, instrumentalizar e propagar, apoiado pelo CNPq. O objetivo principal é desenvolver materiais didáticos sobre solos e divulgá-los na comunidade acadêmica, educação básica e comunidade em geral, isto feito através de vários projetos que constituem o Programa. Nessa etapa, a pesquisa "Produção de material de apoio didático no contexto colaborativo ao ensino de solo", foi realizada no Laboratório de Pedologia e Processos Erosivos em Estudos Geográficos-LAPPEGEO na Universidade Estadual Vale do Acaraú- UVA, no Centro de Ciências Humanas - CCH, Sobral- CE, sendo possível receber visitas monitoradas, as quais se tornaram nosso objeto de análise. $\mathrm{Na}$ oportunidade, foi possível verificar a importância da mesma para a formação dos alunos quando o assunto é solo.

PALAVRAS-CHAVE: Ensino de geografia, Educação em Solos, Visitas Monitoradas.

\section{MONITORED VISITS: A KNOWLEDGE BEYOND THE SCHOOL WALLS}

\begin{abstract}
This article is a step in the Education Program in Soil: knowing, implement and propagate, supported by CNPq. The main objective is to develop teaching materials on soil and disseminate them in the academic community, basic education and community in general, this is done through various projects that make up the program. At this stage the project in question "teaching support material production in collaborative context to the ground education" was held in Pedology and Erosion Laboratory of Geographic - LAPPEGEO Studies at the State University Valley Acaraú- UVA, the Humanities Center - $\mathrm{CCH}$, Sobral, CE, where it was possible to receive visits monitors, which have become our object of study. On that occasion it was possible to verify its importance to the training of students when it comes to ground. This project resulted in a course conclusion monograph.
\end{abstract}

KEY-WORDS: Geography teaching, Soil Education, Monitored Visits.

\footnotetext{
1 Pesquisa desenvolvida através do projeto do CNPq: Educação em Solos: conhecer, instrumentalizar e propagar. Apoio CNPq.

Professor da rede municipal de ensino e graduado em Geografia da Universidade Estadual Vale do Acaraú/UVA. geanbelchior@hotmail.com

${ }^{3}$ Professora Dra. da Universidade Estadual Vale do Acaraú/UVA e coordenadora do Projeto. cleirefalcao@gmail.com
} 
da Alta Paulista

\section{VISITAS VERIFICACIÓN: UN CONOCIMIENTO MÁS ALLÁ DE LAS PAREDES DE LA ESCUELA}

\section{RESUMEN}

Este artículo es un paso en el Programa de Educación en suelo: conocer, aplicar y difundir, apoyado por el CNPq . El objetivo principal es el desarrollo de materiales didácticos en los suelos y difundirlas en la comunidad académica, la educación básica y la comunidad en general, esto se hace a través de diversos proyectos que conforman el programa. En esta etapa del proyecto en cuestión "la enseñanza de apoyo a la producción de material en el marco de colaboración para la formación de tierra" se celebró en Edafología y Laboratorio Erosión de Estudios Geo - LAPPEGEO en el Valle de la Universidad Estatal de Acaraú- UVA, el Centro de Humanidades - CCH, Sobral CE, donde fue posible recibir visitas monitores, que se han convertido en nuestro objeto de estudio. En esa ocasión fue posible verificar su importancia para la formación de los estudiantes a la hora de fundamentar. Este proyecto dio lugar a una monografía supuesto conclusión

PALABRAS CLAVE: Educación Geografía, Educación Suelos, Visitas Guiadas.

\section{INTRODUÇÃO}

O ensino do solo na educação básica é pouco ou quase nada estudado, acarretando na falta de conhecimento de um elemento importante dentro do espaço geográfico. Destaca-se que 0 mesmo é bem estudado nos ambientes acadêmicos (universidades), mas não tratado com importância que merece no Ensino Básico, (ALMEIDA e COSTA FALCÃO, 2012).

Ainda, de acordo com as autoras, há não valorização do estudo do solo no Ensino Básico se deve a várias problemáticas, dentre elas, as dificuldades dos professores em trabalhar alguns conteúdos de geografia que dirá da temática em apreço e ao excesso de conteúdos estabelecidos, deixando geralmente a parte física para o último bimestre e, a temática solo acaba não sendo contemplada devido ao tempo, e, quando o conteúdo é explicado o professor só realizada uma breve explanação costumeira não evidenciando os complexos elementos do solo que são componentes que direta-indiretamente influi na vida, portanto, evidentemente precisamos para a nossa sobrevivência.

Outra dificuldade clara a ser superada é a existência de pouco material didático que aborda a temática no bojo da discussão e, quando existem, apresentam deficiências e definições equivocadas. Então, os estudantes acabam não tendo acesso as informações úteis adequadas as suas realidades.

Dessa forma, o professor precisa traçar novos meios de construir a aprendizagem, buscando incentivar os alunos para o conhecimento crítico e autônomo aquele que o ensino de geografia tanto busca. 
Para contribuir com os parâmetros para o ensino de geografia com prioridade para o que remete a ensino de solo, refletimos nessa pesquisa as visitas monitoradas em laboratório de pedologia com a peculiaridade de ser um método ativo e interativo que provoca um envolvimento maior do aluno com o objeto de estudo, buscando popularizar o conhecimento a respeito do solo, fazer a ligação da escola com a universidade e criar reflexões acerca da importância do solo para manutenção da vida na Terra.

Apesar de algumas universidades, dentre elas: Universidade Federal do Paraná-UFPR, Universidade Estadual Vale do Acaraú-UVA, Universidade Federal de Viçosa-UFV, Universidade Estadual Paulista- UNESP, e outras já realizarem trabalhas para divulgar a significância do solo para o meio ambiente, percebe-se que o conhecimento desse elemento essencial à dinâmica de funcionamento do ecossistema ainda é restrita. Entretanto, destacar e divulgar a importância que tem o solo é um dos objetivos da visita monitorada, assim concordamos com Costa Falcão (2014, p.183) quando diz "as visitas monitoradas fazem parte de um projeto: Venha conhecer o solo no LAPPEGEO: vai ser divertido e você vai aprender um Educativo". O referido projeto está inserido no Programa de Educação em Solos: conhecer, instrumentalizar e Propagar.

Costa Falcão (2014, p.175) ressalta que:

O programa tem como finalidade a difusão do conhecimento em solos numa perspectiva de integração da natureza e da sociedade, busca estimular 0 conhecimento, a troca de informações, ideias e experiências. Nesse processo educativo, as pessoas precisam: (a) conhecer o elemento solo, entendido como um componente do ambiente natural essencial ao desenvolvimento; (b) se instrumentalizar para que sua compreensão se torne acessível; e (c) propagar o conhecimento, pois, a falta de informação traz como consequência o desequilíbrio ambiental.

\section{O DIA-A-DIA DO LABORATÓRIO LAPPEGEO}

As visitas monitoradas que ocorrem no Laboratório de Pedologia e Processos Erosivos em Estudos Geográficos- LAPPEGEO da Universidade Estadual Vale do Acaraú-UVA, fazem parte do projeto: produção de material de apoio didático no 
contexto colaborativo ao ensino de solo. Segundo Costa Falcão (2014, p.183) as visitas monitoradas têm como objetivo:

[...]proporcionar aos alunos o entendimento do estudo do solo através do contato direto com materiais de apoio didático no sentido de estimulara participação dos alunos contribuindo no processo de ensino aprendizagem.

As visitas são guiadas por acadêmicos do curso de licenciatura em geografia estes são bolsistas do PIBID, FUNCAP, CNPq, PBU, pelo técnico do laboratório e professora orientadora do projeto que esclarecem as dúvidas que visitantes apresentam e divulgam as pesquisas e materiais de apoio didático que são feitas no LAPPEGEO.

Os materiais didáticos são desenvolvidos desde 2009. São materiais do cotidiano do aluno, tais como garrafa PET, folhas A4, cola, recipientes de vidro ou plástico, água e solo, são materiais simples mais se bem utilizados contextualizam a teoria. Segundo (SACRAMENTO e FALCONI, 2011, p.03):

\begin{abstract}
A prática do ensino dos solos permite que o aluno, além de utilizar materiais diferenciados do cotidiano escolar, como brita, areia, argila. Água, ou outros materiais de modelagem, compreendam os modelos ou as informações que estão dentro das sequencias das aulas, na qual o professor deve associar acontecimentos do cotidiano para organizar o raciocínio espacial do aluno em relação às mudanças na paisagem.
\end{abstract}

Os visitantes tem a oportunidade de participar ativamente do conhecimento acerca do solo, pois, durante a visita podem fazer indagações para os monitores e manusear os materiais de apoio didático.

As visitas monitoradas associam teoria e prática. A teoria serve como fundamentação para a prática, a prática é a explicação de todos os materiais de apoio didáticos, que foram confeccionados pelos próprios alunos bolsistas do laboratório. Os materiais didáticos têm como função facilitar o ensino e aprendizagem do solo.

Um dos pontos fundamentais nas visitas é a divulgação da importância que o solo tem para a dinâmica do funcionamento dos ecossistemas terrestres, além de abrir janelas para a divulgação e o fortalecimento do conhecimento do solo, com isso, a finalidade das visitas é conscientizar os cidadãos (professores e alunos) para atuarem de forma consciente na realidade circundante. 
Durante a visita os alunos conhecem os minerais, rochas e fósseis que integram o museu de Rochas e Minerais da Universidade Estadual Vale do AcaraúUVA (Figura 1a). Em seguida, o LAPPEGEO oportuniza aos alunos conhecerem os equipamentos e materiais de apoio didático que vem sendo produzido através do projeto. Temos ainda a possibilidade de realizar atividades práticas com o uso dos kits experimentais, associando a teoria vista em sala de aula com a prática lúdica dos recursos (Figura 1b). Sobre os materiais de apoio didático Costa Falcão (2014, p.185) nos fala que:

Os resultados confirmam a aprovação da utilização dos materiais como ferramenta de apoio que auxiliam os alunos na aquisição dos conhecimentos científicos de forma eficaz e significativa.

Figura 1: Imagens das visitas monitoradas no LAPPEGEO, (a) guarda mirim de sobral, durante apresentação dos minerais e rochas; (b) alunos pintando com a tinta feita de solo.

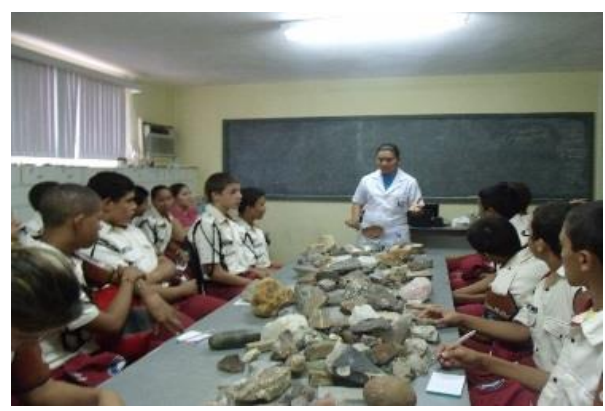

$1 \mathrm{a}$

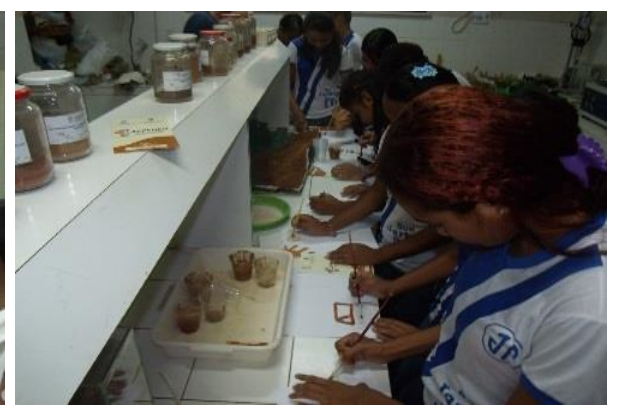

$1 b$

FONTE: LAPPEGEO, 2013.

\section{O ENSINO DE GEOGRAFIA E A CONTRIBUIÇÃO DOS RECURSOS DIDÁTICOS PARA O ENSINO-APRENDIZAGEM DO CONTEÚDO SOLO}

Ensinar geografia na atualidade é um desafio a ser enfrentado pelo professor. Diante de tantas problemáticas que a sala de aula apresentam a falta de apoio pedagógico ao profissional, falta de material didático, salas sem infraestrutura adequada para realização da prática docente, isso tudo acaba refletindo negativamente no processo de ensino-aprendizagem da disciplina de geografia (COSTA FALCÃO, 2014).

Especificamente falando do ensino do solo na disciplina de geografia a problemática é ainda mais agravante, pouca atenção é dada a este conteúdo. Fazendo uma análise de como é trabalhado o assunto solos na ciência geográfica 
na educação básica, percebe-se a banalização do mesmo. Pouco se vê trabalhar em sala de aula o respectivo assunto, fato este verificado em Silva et al (2008).

Torna-se, ainda, mais agravante quando feito uma análise dos materiais destinados à aprendizagem dos solos na escola, quando os livros didáticos praticamente não trazem nada sobre o conteúdo solo. O pouco abordado dá-se de forma simplória e fora do contexto do aluno.

Sabemos que o livro didático, quadro, giz ou pincel são recursos didáticos considerados tradicionais, mas importantes no processo de transmissão do conhecimento. No entanto, com a globalização e as inovações tecnológicas esses recursos por si só acabam, muitas vezes não dando conta de efetivar na prática o desejado quanto a prática docente.

Portanto, cabe ao profissional conciliar a favor da aprendizagem o uso destes recursos, considerados tradicionais, às novas metodologias. De acordo com os parâmetros curriculares nacionais (PCN's), estabelecidos pelo (MEC, 1997, P.67) determinam que:

é importante considerar que o livro didático não deve ser o único material a ser utilizado, pois a variedade de fontes de informação é que contribuirá para o aluno ter uma visão ampla do conhecimento.

A variedade de recursos didáticos contribui para o aluno ampliar sua visão do conhecimento que está sendo abordado, principalmente na sociedade da tecnologia e a informação que estamos vivendo, o professor ao trabalhar como único recurso didático, o livro, o quadro, o giz ou o pincel contribui cada vez mais para a visão que os alunos têm da disciplina de geografia, em que a maioria dos alunos a tem como uma disciplina desinteressante e sem significado para as suas vidas. Com isso (SILVA e MUNIZ, 2012, p.65) afirmam que:

O recurso didático, por sua vez, não tem a capacidade de garantir inteiramente a aprendizagem do aluno, mas desperta nesse um interesse maior na aula, pois oferece ao educando a oportunidade de trabalhar com elementos que 0 permitam ser protagonista na construção do conhecimento.

A variedade dos recursos didáticos vem contribuir no ensino-aprendizagem dessa maneira, ao se utilizar os recursos didáticos, eles podem despertar 0 interesse e a curiosidade dos alunos em aprender Geografia e o conteúdo solo (COSTA FALCÃO, 2014). 
O professor de Geografia variando sua prática talvez consiga superar a geografia tida como tradicional. $O$ recurso didático quando bem utilizado tem esse papel de melhorar o ensino, no entanto o professor deve se posicionar diante desses recursos, o mesmo deve saber utiliza-los, (SILVA e MUNIZ, 2012, p.65) esclarecem que:

O importante é o educador ter ciência de que os recursos didáticos por si só não têm a capacidade de produzir aulas construtivas. Cabe ao professor a decisão de contribuir na educação dos alunos e prepará-los para intervir na sociedade de forma crítica e consciente.

Oliveira (2003) coloca que, o professor deve ter autonomia em sua prática, deve ter o pleno domínio do recurso didático que irá utilizar, pois ao contrário não conseguirá alcançar as metas pré-estabelecidas e esperadas quando pensado na adoção destes recursos. Importante salientar que por se só o recurso não produzirá aulas construtivas, aulas que venham contribuir na educação dos alunos e preparálos para interferir na sua realidade de forma crítica e consciente. Cabe ao profissional saber utilizá-los a favor do processo de aprendizagem dos estudantes, no contrário se o educador não souber utilizar tais recursos didáticos a favor da sua didática, o mesmo será "dominado" pelo recurso adotado, como aconteceu com o livro didático. Argumenta o autor, que nesse processo o professor foi perdendo ou, então, nem teve a oportunidade de formar a sua condição de produtor de conhecimentos. Ele se tornou ou foi transformado em um mero repetidor dos conteúdos dos livros didáticos.

Daí, caberá a cada educador construir sua prática de ensino, pois não existe uma prática global a ser seguida por todos, cabe ao professor analisar qual prática de ensino é mais adequada para a sua realidade e a realidade dos seus alunos. Nas visitas monitoradas os materiais didáticos são bastante explorados pois, acredita-se na sua eficiência no ensino aprendizagem. 


\section{OS CAMINHOS DA PESQUISA: O PERCURSO ESCOLHIDO PARA A SUA REALIZAÇÃO.}

Para cumprimento dos objetivos propostos foram aplicados questionários aos visitantes (professores e alunos) das escolas que visitaram o LAPPEGEO no ano de 2013, pretendendo assim, avaliar a qualidade e eficiência do que foi exposto.

Nos questionários foram feitas indagações sobre esta ação educativa. Perguntas relacionadas sobre qual a forma ideal do uso dos materiais didáticos, a adequação do tempo, se as expectativas dos visitantes foram atendidas e se os mesmos indicariam as visitas a outras instituições. No final, destinou-se um espaço reservado para sugestões e críticas.

A partir dos questionários, obtevem-se, resultados qualitativos. Morais (2012), considera qualitativo quando possuem uma riqueza de detalhes relacionados a pessoas, lugares e conversas, sendo estes de complexo tratamento estatístico.

No ano de 2013 ocorreu um total de 15 visitas monitoradas. A escola que mais frequentou o laboratório foi a Escola Ministro Jarbas Passarinho, isto em função do fácil acesso que fica ao lado do Centro de Ciências Humanas - $\mathrm{CCH}$, localizada no bairro do Junco. Através de conversa informal os professores afirmam que trazem eles ao laboratório não simplesmente pelo fato da proximidade mas porque a visita dos alunos ao LAPPEGEO se torna um momento rico em aprendizagem que repercute em suas vidas e serve como complementação para o conteúdo que está sendo abordado. Destacam, ainda, que a visita contribui para a formação cidadã dos alunos, porque no momento que os alunos conhecem e refletem sobre o solo nessa visita monitorada, eles podem atuar conscientemente na realidade que os circunda.

Com a diversidade de escolas e visitantes que frequentaram o LAPPEGEO no ano de 2013, a pesquisa pôde abranger um público variado. Foi aplicado, sendo no município de Sobral, um questionário para 5 turmas do Ensino Fundamental: Escola de Ensino Fundamental e Médio Ministro Jarbas Passarinho, com duas turmas, um total de 48 entrevistados, Colégio Sant'Ana, com uma turma de 38 alunos participantes da pesquisa, a Escola Maria José com uma turma de 22 alunos e de Reriutaba, CE, a Escola João Furtado Filho, com 32 alunos, totalizando 140 alunos entrevistados. 
No contexto geral, duas Escolas são da rede pública de ensino: Escola Ensino de Ensino Fundamental e Médio Ministro Jarbas Passarinho e a Escola Maria José e outras duas são da rede particular: Colégio Sant'Ana e a Escola João Furtado Filho.

Foram expostos e disponibilizados para os alunos: visitas ao museu de minerais e rochas, tintas feitas com pigmentos do solo, jogos lúdicos e breve palestras sobre o tema solo.

\section{RESULTADOS E DISCUSSÕES:}

No transcorrer das atividades desenvolvidas durante as visitas monitoradas percebeu-se o entusiasmo dos alunos e professores, podendo afirmar a eficácia da utilização dos materiais como ferramenta de apoio que auxiliam os alunos na obtenção do conhecimento sobre o solo. Destaca-se, ainda, a satisfação dos visitantes por estarem na Universidade, para muitos destes o momento foi único.

Um material didático que chama muito a atenção dos alunos são as tintas feitas com pigmentos dos solos (Figura 2a), é um material fácil de fazer e que faz muito sucesso entre os visitantes. A expressão de satisfação no rosto dos visitantes quando sabem da possibilidade de pintar com tinta feita do solo, juntamente com essa surpresa também gera certa curiosidade em entender como isso é possível. Assim sendo, pegando isso a favor da aprendizagem, é dado início a apresentação do conteúdo solo.

Notou-se nas falas de alguns alunos quando perguntado sobre o solo, o desconhecimento da temática, e um agravante é a visão de desprezo do conteúdo. No entanto, é perceptível que a desconstrução desta visão para com o assunto solo é superada no decorrer da visita monitorada. Os alunos saem do laboratório com outra visão, sabendo de toda importância que este elemento natural tem para o funcionamento da vida em nosso planeta.

As curiosidades (Figura 2a) e os jogos lúdicos (Figura 2b) são materiais que tem uma expressão muito significante em se tratando de eficiência de ensinoaprendizagem, pois quando os mesmos são trabalhados corretamente conseguem despertar o interesse dos alunos, além de desenvolver a inteligência, os sentidos, a afetividade, a vivência de regras, o relacionamento social e outras habilidades. 
Assim a ludicidade contribui diretamente para uma melhor aprendizagem do conteúdo em questão. No que se refere à ludicidade.

Almeida e Costa Falcão (2012, p.02) reforçam que:

\begin{abstract}
O brincar é um processo intrínseco do ser humano, que desde a infância vai construindo conhecimentos através das mais diversas brincadeiras. Brincando a criança se exercita, descobre, erra, acerta, imagina, cria suas próprias regras, conta histórias, constrói, destrói, transforma e assim vai desenvolvendo sua aprendizagem naturalmente. A ludicidade, portanto, possibilita desenvolver o conhecimento sem tantas exigências, fazendo dessa aprendizagem um momento satisfatório e agradável.
\end{abstract}

É com essas perspectivas que está sendo trabalhada a educação em solos no LAPPEGEO, fazendo com que a aprendizagem seja um momento prazeroso para os alunos, então, de forma lúdica vai sendo desconstruído a visão errônea a respeito do conteúdo e reconstruindo de forma correta o conhecimento acerca do solo, desenvolvendo o conhecimento sem tantas exigências. $E$ sabendo da grande importância de utilizar o lúdico como estratégia metodológica a favor da aprendizagem, Almeida e Costa Falcão (2012, p.03) falam que o lúdico possibilita a relação da criança com o conteúdo, pois através da atividade lúdica e do jogo, a criança forma conceitos, estabelece relações de lógica, integra ideias, estimula a observação e vai desenvolvendo o seu aprendizado.

Trabalhar com os jogos faz com que desperte o interesse dos alunos para a temática que está sendo abordada, portanto, trabalhar o conteúdo solo com os jogos lúdicos faz com que os alunos aprendam brincando, tornando o momento da aprendizagem prazeroso e divertido. Em se tratando de jogos Almeida e Costa Falcão (2012) argumental que "Os jogos e atividades práticas contribuem para uma melhor concentração nos conteúdos." Assim, através de um momento prazeroso utilizando os jogos didáticos os alunos podem conciliar divertimento e aprendizagem.

O alvo principal das visitas monitoradas são os alunos. Desta forma, saber as suas opiniões sobre essa ação educativa que vem sendo praticada no LAPPEGEO é de grande importância para a pesquisa, analisando as respostas verifica-se que uma das perguntas que teve o maior grau de descontentamento foi a do tempo de duração que não foi satisfatório. Dos 140 entrevistados 14\% deles responderam que não foi satisfatório, isso vem indicar que as visitas necessitam de mais tempo, mostrando que o momento de aprendizagem dentro do laboratório envolvendo os alunos com os diversos materiais poderá ser mais explorado a favor da 
aprendizagem, assim, sendo percebe-se que eles adorariam ficar mais tempo dentro do laboratório.

Nas perguntas suas expectativas foram atendidas com a visita? Explicação dos monitores foi satisfatória? e o uso dos materiais didáticos contribuíram na sua compreensão? Obtiveram respostas semelhantes com um total de $94 \%$ dos entrevistados respondendo "SIM" e 6\% deles respondendo "NÃO". Analisando os resultados verifica-se que a visita como um todo está conseguindo atender as necessidades dos alunos, no que se refere a aprendizagem do conteúdo solo.

Além disso, pôde-se detectar com as análises dos questionários, que aqueles alunos vindos das escolas da rede privada de ensino, quando ao responder as perguntas, um fato chamou atenção, as respostas dadas para a pergunta dos materiais didáticos, se eles contribuíram na sua compreensão, verificou- se que uma porcentagem maior respondendo "NÃO".

Figura 2: (a) Alunos confeccionando e pintando com a tinta feita de solo; (b) imagens de alguns jogos lúdicos.

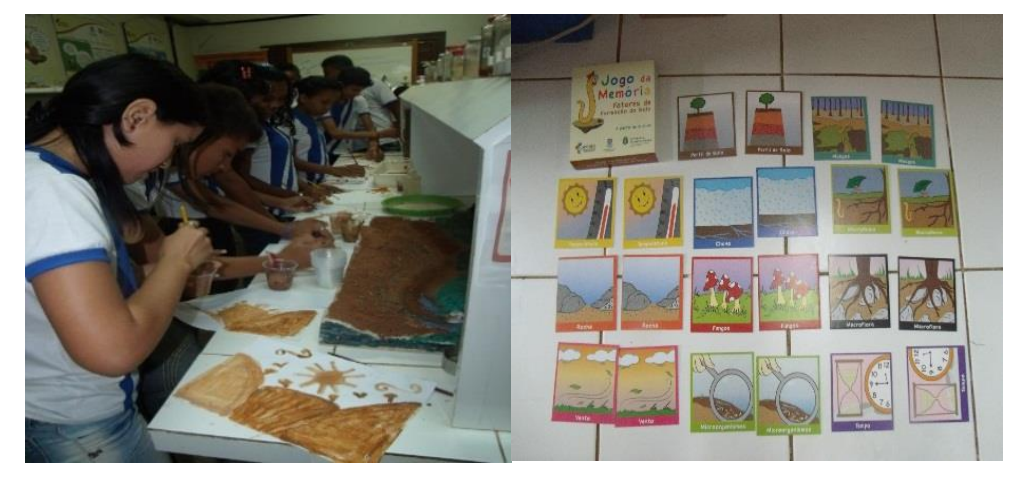

$2 \mathrm{a}$
$2 b$

Fonte: LAPPEGEO, 2013.

Fazendo uma análise desta constatação, chega-se a conclusão que o fato deles estarem inseridos numa outra realidade, onde a sua escola por se tratar de uma escola privada, os possibilita o contato com ferramentas parecidas e diversificadas, e, quando comparadas as escolas da rede pública, assim não gerando tanta expectativa com os materiais utilizados.

Quando sugerido a eles, alunos, a fazerem sugestões, críticas, e opinar sobre a visita monitorada, percebeu-se a satisfação destes, como pode ser visto nos depoimentos: "Nada a aula foi ótima e satisfatória" (a), "simplesmente nada, porque foi muito legal que eu nunca tinha visto, adorei!" (b), "ótimo adorei, recomendarei a 
todos" (c). "Eu virei mais vezes para aprender um pouco mais." (d), "Foi ótimo e recomendo a todos, amei e consegui tirar todas minhas dúvidas e ainda aprendi mais e para mim não precisava mais de nada, foi muito bom!", (e), "Queria mais tempo, porque gostei muito." (f), "nada, pois os alunos da faculdade deram uma aula como professores formados". As respostas ressaltam a importância dos monitores do laboratório na apresentação do conteúdo.

Percebeu-se então, a importância do monitor nesse processo de transmissão do conteúdo em questão, pois fica claro na fala de um dos alunos a satisfação dos mesmos com a explicação dos monitores, afinal é com os monitores que os alunos interagem e tiram suas dúvidas, se tornando importantes no processo de aprendizagem.

Porém, a partir das sugestões, críticas, sugeridas aos visitantes no final da visita, observou-se na fala destes alunos outros aspectos importantes pertinentes na visita monitora: "Maior espaço para a apresentação" (f), "Foi bom, mas faltou mais campos, lugares para fazerem suas experiências" (g), "Expandir um pouco mais os espaços e melhorar na climatização" (h).

Analisando suas colocações percebe-se que suas análises fazem sentido, devido ao pouco espaço interno no laboratório que dificultam às vezes desenvolver certos experimentos. Como geralmente as turmas que visitam o laboratório são numerosas, uma média de 35 alunos por visita, o espaço do laboratório fica bastante restrito e a realização de alguns experimentos às vezes se torna difícil.

Outro problema citado pelos alunos que visitaram o laboratório, se refere a climatização do ambiente interno, como as visitas ocorrem nos dois períodos (manhã/tarde), as visitas realizadas no período da tarde geralmente acabam gerando um desconforto no interior do laboratório, como as turmas na maioria das vezes são numerosas, com isso o climatizador artificial acaba não suprindo a demanda, assim o interior do laboratório se torna desagradável, podendo interferir na aprendizagem dos alunos.

Avaliando outras opiniões dos alunos, alguns responderam que era necessário acrescentar um maior número de visitantes, como fica evidente no depoimento de alguns dos estudantes: "As escolas deveriam trazer mais alunos para conhecer", (aluno i), "Os alunos deveriam vim mais no LAPPEGEO, porque é um local que a gente aprende muito." (aluno j). Estas sugestões dos alunos são bem 
chamativas pois, eles criticam o espaço físico do laboratório e ao mesmo tempo comprovam que as visitas monitoradas conseguem despertar o prazer de aprender sobre o solo.

Com um total de 5 professores participando da pesquisa, ao analisar suas respostas verifica-se que os mesmos estão satisfeitos com os caminhos que são trilhados no decorrer da visita monitorada, pois $100 \%$ dos entrevistados responderam "SIM" em todas as perguntas. Os resultados dos questionários são bem chamativos, pois, todos os professores tiveram a mesma opinião nas perguntas, indicando que a visita supriu o que o professor buscava quando pensou na visita ao laboratório.

No que diz respeito às sugestões e críticas, verifica-se que os professores ficaram satisfeitos com a visita, como pode ser observado na fala de alguns: "nada, apenas divulgar mais o laboratório, que o mesmo é muito rico em materiais didáticos", (Professora a), "Divulgar mais o laboratório, por não conhecer o trabalho de vocês, a escola analisa a visita como um passeio e na maioria das vezes não disponibiliza transporte." (Professora b).

O que vem ser bem chamativo nessas sugestões é que os professores sempre batem na tecla da divulgação, segundo eles o LAPPEGEO deveria divulgar os seus trabalhos. Vem chamar atenção também nas suas sugestões a visão que a escola tem da visita monitorada que enxerga a mesma como sendo um passeio e não analisam como processo de aprendizagem e de troca de saberes entre seus participantes (alunos, professores e monitores), e tentar mudar o pensamento das pessoas de que educação não só se realiza no ambiente escolar é uma das metas a ser superada.

\section{CONCLUSÕES}

Devemos ressaltar a importância de buscar sempre melhorar o ensino de solo na disciplina de geografia, adotando métodos e metodologias que possam levar aos alunos ao entendimento da sua dinâmica quanto recurso natural.

Através das análises dos resultados obtidos pela aplicação dos questionários, verifica-se que esta ação educativa feita por intermédio das visitas monitoradas que 
acontece no LAPPEGEO, está sendo um ótimo recurso para a divulgação e conscientização das pessoas (alunos e professores) sobre a importância que tem este tema, fazendo-se assim a educação em solos.

Espera-se que os participantes das visitas monitoradas consigam fazer a leitura do espaço, e que eles possam compreender o que ocorre em seu entorno e venha atuar conscientemente na realidade que os circunda, criando uma "consciência pedológica", ou seja, efetivando na prática a educação em solos.

Sabendo que o ensino de Geografia tem como característica trabalhar em cima da conscientização das pessoas quanto são cidadãos ativos, capazes de entender a dinâmica dos espaços que os cercam para assim ter o discernimento para desenvolver suas atividades diárias conscientemente daí serem importantes as práticas inovadoras tais como as apresentadas captando a participação ativa do aluno.

Portanto, caberá ao professor criar metodologias que venham abordar a realidade do aluno, pois as informações contidas nos livros didáticos dificilmente trata a realidade dos mesmos, dessa forma o professor precisa traçar novos meios de se chegar a aprendizagem e buscar incentivar os alunos para o conhecimento mais aprofundado sobre o solo.

Assim, através dos materiais didáticos com a temática solo, nota-se que estes ganham força por utilizar-se de métodos e metodologias ativos e interativos que provocam um envolvimento maior do aluno com o conhecimento.

\section{REFERÊNCIAS BIBLIOGRÁFICAS}

ALMEIDA, Carliana L.; FALCÃO, Cleire L. C. O lúdico como instrumento facilitador da aprendizagem: Uma abordagem ao estudo do solo no ensino de geografia. Revista Homem, Espaço e Tempo. Centro de Ciências Humanas da Universidade Estadual Vale do Acaraú/UVA. Ano 1, número 1 , setembro de 2012. ISSN 1982-3800.

COSTA FALCÃO, C. L. Programa de educação em solos: conhecer, instrumentalizar e propagar. In: FALCÃO SOBRINHO, J.; LINS, J. R. F. J. (Org.) EXTENSIONANDO: Cultivando saber na escola e na comunidade. Fortaleza: Expressão Gráfica e Editora, 2014.

OLIVEIRA, A. U.; Educação e ensino de geografia na realidade Brasileira. IN: OLIVEIRA, Ariovaldo U. (Org.); Para onde vai o ensino de geografia?. São Paulo: Contexto, 2003.

SACRAMENTO, A. C. R.; FALCONI, S. Educação geográfica e ensino de solos: uma experiência em sala de aula. Apresentado em EI XIII Encuentro de Geógrafos da américa Latina, 25 al 29 de Júlio Del 2011 Universidad de costa rica-Universidad nacional, Costa Rica.

SILVA, C, S.; FALCÃO, C, L, C.; SOBRINHO, J, F. O ensino do solo no livro didático de 
geografia. Revista Homem, Espaço e Tempo. Centro de Ciências Humanas da Universidade Estadual Vale do Acaraú/UVA. Ano II, número 1, março de 2008. ISSN 1982-3800.

SILVA, V.; MUNIZ, A. M. V.; A geografia escolar e os recursos didáticos: o uso das maquetes no ensino-aprendizagem da geografia. Geosaberes, Fortaleza, v. 3, n. 5, p. 62-68, jan. / jun. 2012. 